\title{
The role of sympathetic nervous activity in renal injury and end-stage renal disease
}

\author{
Kazuko Masuo $^{1,2}$, Gavin W Lambert ${ }^{2}$, Murray D Esler ${ }^{2}$, Hiromi Rakugi ${ }^{3}$, Toshio Ogihara $^{3}$ \\ and Markus P Schlaich ${ }^{4}$
}

Sympathetic nervous system hyperactivity is observed in patients with renal injury, renovascular hypertension, chronic kidney disease (CKD) and end-stage renal disease (ESRD). Elevated sympathetic activity is of prognostic relevance in that plasma norepinephrine concentrations predict survival and the incidence of cardiovascular events in patients with ESRD, as well as future renal injury in normotensive healthy subjects with renal function in the normal range. Renal injury, CKD and ESRD are often associated with obesity, and its common sequelae hypertension and diabetes. In fact, hypertension and diabetes mellitus are the main causes of ESRD in western societies and together account for approximately more than $50 \%$ of ESRD incidence in the United States and Japan. Obesity also leads to increases in the incidence of cardiovascular diseases. Several clinical and epidemiological studies have clearly documented that heightened sympathetic nervous activity has an important role in the onset and maintenance of obesity and hypertension. Elevated sympathetic nervous activity may actually represent an important mechanism contributing to the onset and maintenance of renal injury at least in part through its concomitant adverse effects on obesity and hypertension. Understanding the contribution of sympathetic nervous hyperactivity to the onset and maintenance of renal injury might aid in the prevention and treatment of renal injury, CKD and ESRD. Very recently, renal sympathetic denervation was shown to be a potentially novel therapeutic strategy in resistant hypertension. In addition, renin-angiotensin system inhibitors are recommended as the initial therapy because of their renal protective effect, especially in hypertensive patients with type 2 diabetes or with proteinuria. The purpose of this review is to provide an overview of our current knowledge on the relationships between sympathetic nerve activity and renal function to further our understanding of the precise roles of sympathetic nerve activity in renal injury, particularly in the context of obesity and hypertension. These insights may be useful to improve prevention and treatment of renal injury in these patients.

Hypertension Research (2010) 33, 521-528; doi:10.1038/hr.2010.35; published online 26 March 2010

Keywords: end-stage renal disease; plasma norepinephrine; renal injury; sympathetic nerve activity

\section{INTRODUCTION}

Elevated sympathetic nervous activity is recognized as an important mechanism involved in cardiovascular complications in humans. ${ }^{1}$ Sympathetic nerve hyperactivity leads to arterial blood pressure elevation, triggers arterial damage and results in cardiovascular events. There is consistent evidence that high plasma norepinephrine levels, which do provide an index of sympathetic nerve hyperactivity, predicts mortality in patients with cardiovascular diseases such as chronic congestive heart failure, ${ }^{2}$ asymptomatic left ventricular dysfunction ${ }^{3}$ and end-stage renal disease (ESRD). ${ }^{4}$ Petersson et al. ${ }^{5}$ indicated that increased cardiac sympathetic nervous activity in renovascular hypertension might lead to high cardiovascular mortality and morbidity. Renal injury also predicts the development of cardiovascular disease. ${ }^{6}$ Therefore, early stage renal injury may be used as one of the markers of risk for the development of future serious cardiovascular events.
The association between hypertension, obesity and chronic kidney disease (CKD) is well recognized. ${ }^{7-9}$ Obesity and hypertension also leads to an increase in the incidence of metabolic diseases such as diabetes mellitus, which is frequently associated with renal injury (proteinuria/microalbuminuria). In the majority of cases, ESRD occurs as a result of complication of diabetes or hypertension. ${ }^{6}$ The incidence of hypertension, one of the primary etiological factors for ESRD development, is significantly higher with obesity, suggesting that obesity per se may be an independent factor for chronic renal disease development. ${ }^{8,10}$ Obesity is also frequently observed in patients with diabetes mellitus ${ }^{11,12}$ and hypertension, ${ }^{13}$ and both diabetes and hypertension together account for approximately more than $50 \%$ of ESRD incidence in Japan and the United States. ${ }^{6,14}$ In many clinical and epidemiological studies, elevated sympathetic nerve activity has been documented in both obesity and hypertension. ${ }^{15-20}$ Thus, one

\footnotetext{
${ }^{1}$ Nucleus Network Ltd., Baker IDI Heart and Diabetes Institute, Melbourne, Victoria, Australia; ${ }^{2}$ Human Neurotransmitter Laboratory, Baker IDI Heart and Diabetes Institute, Melbourne, Victoria, Australia; ${ }^{3}$ Department of Geriatric Medicine, Osaka University Graduate School of Medicine, Suita, Osaka, Japan and ${ }^{4}$ Neurovascular Hypertension and Kidney Disease Laboratory, Baker IDI Heart and Diabetes Institute, Melbourne, Victoria, Australia

Correspondence: Professor K Masuo, Baker IDI Heart and Diabetes Institute, 75 Commercial Road, Melbourne, Victoria 3004 , Australia.

E-mail: kazuko.masuo@bakeridi.edu.au

Received 20 June 2009; revised 22 December 2009; accepted 3 February 2010; published online 26 March 2010
} 
could speculate that the elevated sympathetic nervous activity that is associated with obesity and hypertension might have an important role in the onset and maintenance of renal injury regardless of its severity. ${ }^{20,21}$

Many investigators have observed elevated levels of plasma norepinephrine and heightened muscle sympathetic nerve activity in patients with ESRD in cross-sectional studies, ${ }^{22,23}$ but few investigations have simultaneously taken into account sympathetic nerve activity and renal function in the same study population followed longitudinally for several years to clarify the relationships between sympathetic nerve activity with the onset and development of renal injury. Observations from these studies indicate that renal injury or ESRD is a consequence of hypertension and obesity. However, the majority of previous studies regarding the relationship between sympathetic nerve activity and renal function have used proteinuria or microalbuminuria as a marker of renal injury. Proteinuria and microalbuminuria are good markers for early stage of renal injury, although renal injury is diagnosed using creatinine clearance. Only one study is available to show that heightened sympathetic nerve activity (high plasma norepinephrine) predicts future renal injury in normotensive, healthy subjects. ${ }^{21}$ Further, this study suggested that the $\beta 2$-adrenoceptor polymorphisms that is associated with the strong linkage of the pathogenesis of obesity and hypertension ${ }^{24-28}$ relates to future renal injury. These findings may indicate a vicious triangle between sympathetic nervous activation, renal injury (ESRD), obesity and hypertension, and that the association may be determined, at least in part, genetic background through heightened sympathetic nerve activity.

The purpose of this article is to provide the current findings on the important, but still not fully clarified, topics including the relationships between sympathetic nerve activity and renal injury. To better understand the contribution of the sympathetic nervous system to the onset and development of renal injury might prevent future ESRD, especially in patients with obesity, hypertension and diabetes, and help to develop rational treatments for those patients with renal injury.

\section{IMPAIRED RENAL FUNCTION (PROTEINURIA, MICROALBUMINURIA AND CREATININE CLEARANCE) PREDICT FUTURE CARDIOVASCULAR DISEASES}

Many epidemiological studies have shown that the presence of microalbuminuria is well established as a marker of cardiovascular risk in diabetes mellitus in hypertensive patients without diabetes. ${ }^{29-31}$ In addition, Farbom et al. ${ }^{32}$ tested whether renal function and microalbuminuria are independent predictors for future cardiovascular disease in 10881 hypertensive patients over a 4.5 -year period. They concluded that microalbuminuria and renal function (creatinine, BUN and creatinine clearance) are independently associated with future cardiovascular events, and that a decrease in creatinine clearance (glomerular filtration rate, GFR), which is strongly associated with microalbuminuria was a precursor for the future cardiovascular events. Their findings suggested that the cardiovascular risk associated with microalbuminuria might depend on the levels of GFR, and that microalbuminuria was one of the better markers of renal injury. Hillege et al. ${ }^{33}$ examined the effect of renal function using creatinine clearance in patients with chronic heart failure. Impaired renal function was a stronger predictor of mortality than impaired cardiac function in patients with chronic heart failure, ${ }^{33}$ thereby suggesting that renal function could strongly predict survival in patients with chronic heart failure. These investigations have shown the importance of renal function as a predictor of the mortality and morbidity of cardiovascular disease.

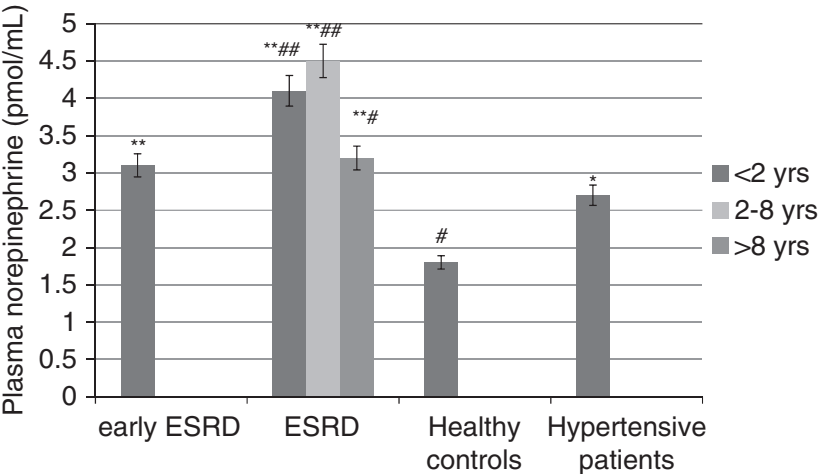

Figure 1 Plasma norepinephrine levels are higher in early ESRD patients without hemodialysis and ESRD patients with hemodialysis than those in body mass index (BMI)-matched healthy normotensive subjects and in BMI- and blood pressure-matched hypertensive patients. ${ }^{*} P<0.050$, ${ }^{*} P<0.01$ vs. healthy controls; ${ }^{\#} P<0.05$, \# $P<0.01$ vs. hypertensive patients. ESRD; patients with ESRD. ${ }^{23}$

\section{SYMPATHETIC NERVE HYPERACTIVITY IN RENAL DISEASE}

Albuminuria/proteinuria vs. sympathetic nerve activity

Merna-Martin et al. ${ }^{34}$ studied the relationships between urinary albumin excretion (UAE) and plasma norepinephrine in 495 subjects using a cross-sectional design. In the multivariate analysis, gender, systolic blood pressure and UAE were associated with plasma norepinephrine levels, and gender, systolic blood pressure and body mass index were associated with epinephrine. After excluding those patients with CKD, the multivariate analysis showed a strong association between high UAE (30 $\mathrm{mg} \mathrm{day}^{-1}$ or more) and elevated norepinephrine and epinephrine levels. Further, Rao et al. ${ }^{35}$ in their examination of the importance of adrenergic polymorphisms and genetic predisposition, observed a strong relationship between UAE and sympathetic nerve activity in twin pairs. The UAE and catecholamines were highly heritable and correlated, suggesting that sympathetic nervous system might mediate early glomerular permeability alterations. Albumin excretion is influenced by multiple adrenergic pathway genes and is polygenic. This study supports the hypothesis that elevated plasma norepinephrine is a cause of renal injury and exert a direct effect on kidney function.

\section{Plasma norepinephrine levels in ESRD}

Elevated sympathetic nervous activity has been reported to have an important role in cardiovascular complications in humans. ${ }^{1}$ Masuo et al. ${ }^{23}$ showed that the sympathetic nervous system, as assessed using plasma norepinephrine levels in patients with ESRD treated with hemodialysis and with early-ESRD without hemodialysis is activated with plasma norepinephrine levels being significantly higher compared with those in blood pressure- and body mass index-matched hypertensive patients or healthy normotensive subjects (Figure 1). Further, this was recognized significantly in subjects with a shorter duration of ESRD compared with those with longer duration, suggesting that sympathetic nerve hyperactivity may be of particular importance in the onset or the early development of ESRD or alternatively, be influenced by long-term renal replacement therapy (hemodialysis). Zoccali et al. ${ }^{9,22}$ examined the relationship between sympathetic nerve activity, again, as indicated using plasma norepinephrine levels, and mortality and cardiovascular events in 228 ESRD patients undergoing chronic hemodialysis without heart failure. They found that $45 \%$ of dialysis patients had significantly elevated plasma norepinephrine 


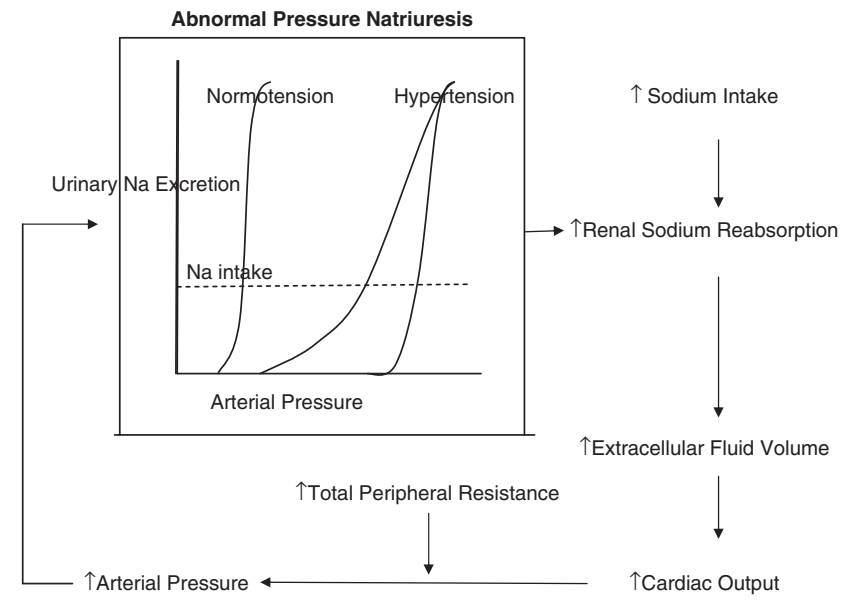

Figure 2 Abnormal pressure-natriuresis causes high blood pressure. ${ }^{39,40}$

levels. One hundred and twenty-four fatal and nonfatal cardiovascular events occurred in 85 patients during the follow-up period $(34 \pm 15$ months). Plasma norepinephrine levels proved to be an independent predictor of all-cause death and of fatal and nonfatal cardiovascular events using a multivariate Cox regression model. They also found that plasma norepinephrine levels were associated with concentric left ventricular hypertrophy in these patients. ${ }^{22}$

\section{Sympathetic nerve hyperactivity in patients with ESRD}

Evidence now strongly indicates a role for the sympathetic nervous system in the pathogenesis of hypertension in renal failure (ESRD). ${ }^{36,37}$ Hypertension occurs commonly and early in renal disease and is paralleled by increases in sympathetic nerve activity, as indicated by increased muscle sympathetic nerve activity and circulating norepinephrine (Figure 1). This appears to be driven by the diseased kidneys, because nephrectomy or denervation has been shown to correct blood pressure and sympathetic nerve activity both in human and animal studies. ${ }^{38}$ One of the important determinants of the sympathetic nerve activity in hypertension in patients with ESRD is most likely abnormal renal sodium excretion. In the normal state, interactions between the kidney and sympathetic nervous system serve to maintain blood pressure and glomerular filtration rate within tightly controlled levels, but in renal failure, a defect in renal sodium excretory function leads to an abnormal pressure natriuresis relationship and activation of the renin-angiotensin system (RAS), contributing to the development of hypertension (Figure 2) and progression of kidney disease. ${ }^{39-41}$ Further, volume overload per se could also be incorporated here. Another mechanism could involve the sympathetic nervous modulation of baroreflex regulation and vasculature tone through the central nervous system and angiotensin II. ${ }^{42}$ Afferent signals from the kidney, detected by chemoreceptors and mechanoreceptors, feed directly into central nuclei regulating sympathetic nerve activity by circulating and brain-derived angiotensin II. ${ }^{43}$ Therefore, the pathogenesis of hypertension in renal failure (ESRD) is complex and arises most likely from the interaction of hemodynamic and neuroendocrine factors. Sympathetic nerve activity has strong relationships with regards to increased risk of cardiovascular disease including hypertension ${ }^{9,22}$ in patients with ESRD and the mortality and morbidity of cardiovascular disease, suggesting that we have to pay much more attention to sympathetic nerve activation in our attempts to adequately treat patients with ESRD.
Sympathetic nerve hyperactivity in ESRD is independent from obesity or hypertension

Sympathetic nerve activity is consistently elevated in patients with ESRD, and in obese subjects and hypertensive patients in crosssectional studies. ${ }^{23,27,28}$ Further, strong relationships between elevated sympathetic nerve activity, hypertension and obesity have been shown. Thus, the question whether elevated sympathetic nervous activity in patients with ESRD is related to their increased blood pressure may arise. Figure 1 illustrates that plasma norepinephrine levels were higher in patients with ESRD than in blood pressure- and body mass indexmatched hypertensive patients or body mass index-matched normotensive subjects (Figure 1), indicating that sympathetic nerve hyperactivity is at least in part independent of increased blood pressure levels or obesity. Further, patients with early-ESRD without hemodialysis had already significantly higher plasma norepinephrine levels compared with hypertensive subjects as well as normotensive subjects. The amount of norepinephrine in plasma is only a fraction of the amount released into the synaptic cleft, and plasma norepinephrine levels were affected by dialysis therapy, so it is difficult to discount that the elevated plasma norepinephrine levels did not derive in part from reduced plasma norepinephrine clearance rather than solely from elevated sympathetic nerve activity. Grassi et al., ${ }^{44}$ however, reported similar results using microneurography. In addition, plasma norepinephrine levels did not change between before- and after-hemodialysis therapy (data was not shown), and between after-hemodialysis therapy and before-next hemodialysis therapy. Thus, one could speculate that plasma norepinephrine levels in ESRD patients may be considered as a part of the sympathetic nerve activity.

Prolonged sympathetic nerve stimulation and elevated circulating norepinephrine levels can induce changes in intra-renal blood vessels. Indeed, catecholamines can induce proliferation of smooth muscle cells and adventitial fibroblasts in vascular wall. ${ }^{45}$ Rao et al. ${ }^{35}$ and Masuo et al. ${ }^{21}$ have shown strong associations between adrenergicrelated polymorphisms, elevated plasma norepinephrine and elevated UAE or future renal injury, suggesting that stimulated sympathetic nerve activity, itself, may independently have a major role of the onset and development of ESRD without obesity or hypertension. However, the precise mechanisms underlying sympathetic activation in CKD and ESRD have not been clarified.

\section{Plasma norepinephrine levels may predict future renal injury}

Masuo et al. ${ }^{21}$ measured renal function (creatinine, BUN and creatinine clearance) and plasma norepinephrine levels annually over a 5year period in nonobese, normotensive men with normal renal function. Subjects who had a significant deterioration of renal function $(\geqslant 10 \%$ increases from baseline of creatinine and BUN or decrease in creatinine clearance) over a 5-year period had higher plasma norepinephrine at the entry period, and greater increases in plasma norepinephrine over 5 years (Figure 3). In this study, subjects who had significant changes in body weight or blood pressure were excluded. Further, subjects who had significantly higher levels of plasma norepinephrine had a higher frequency of the Gly16 allele of the $\beta 2$-adrenoceptor polymorphism ${ }^{21}$ (Figure 4 ). The Gly16 allele of the $\beta 2$-adrenoceptor polymorphism has been shown to be related to obesity, ${ }^{25,27,28}$ hypertension ${ }^{25,28}$ and metabolic syndrome development. ${ }^{26}$ Thus, high plasma norepinephrine levels appear to be a predictor that is determined genetically by the $\beta 2$-adrenoceptor polymorphism (Arg16Gly) for renal injury, obesity, hypertension and metabolic syndrome.

These observations show that plasma norepinephrine levels are strongly linked with the onset and development of renal injury. 


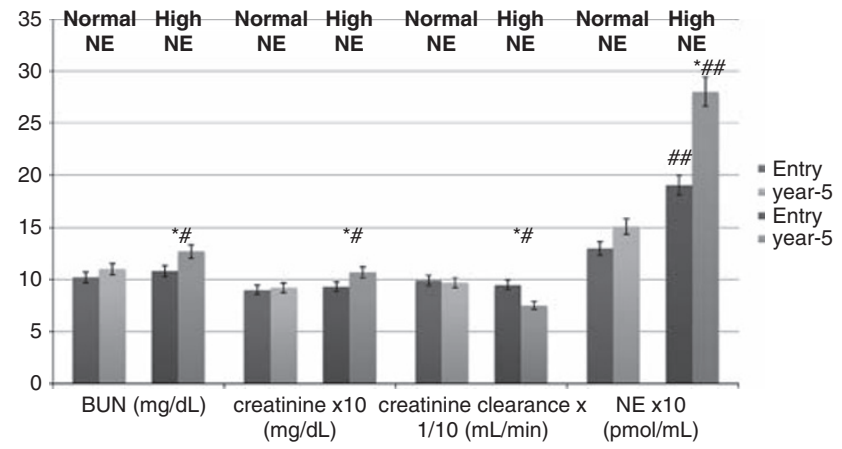

Figure 3 Comparisons of renal function (BUN, creatinine and creatinine clearance) at entry and at year-5 between subjects with normal and high plasma norepinephrine levels at entry period. ${ }^{*} P<0.05,{ }^{*} P<0.01$ vs. values at entry; $\# P<0.05,{ }^{\#} P<0.01$ vs. subjects with normal norepinephrine levels at entry period. NE; plasma norepinephrine concentrations. Normal $\mathrm{NE}$; normal $(\leqslant m e a n+2$ s.d.) plasma norepinephrine concentrations at entry period; High NE, high (>mean+s.d.) plasma norepinephrine concentrations at entry period. ${ }^{21}$

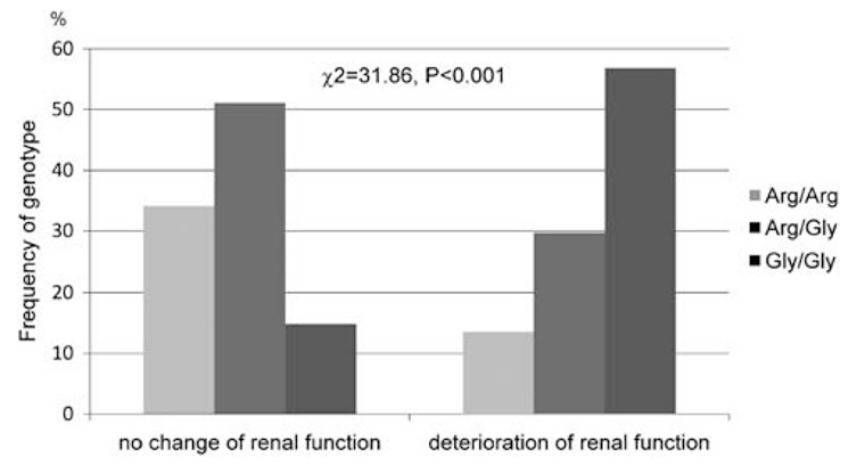

Figure 4 Subjects who had deteriorations of renal function carried higher frequency of the Gly16 allele of Arg16Gly, the $\beta 2$-adrenoceptor polymorphisms. $^{21}$

Although the amount of norepinephrine in plasma influenced by several factors, such as the rate of reuptake into nerve endings or extra neuronal cells, the density of neuroeffector junctions and the metabolic clearance rate, plasma norepinephrine measurements appears to represent a useful marker of sympathetic nerve activity, particularly in large cohorts and in long-term follow up studies. In our experience, forearm venous plasma norepinephrine concentrations correlate closely with the whole-body rate of norepinephrine spillover to plasma (Figure 5), ${ }^{46}$ and muscle sympathetic nervous activity determined using microneurography ${ }^{47,48}$ This suggests that forearm venous plasma norepinephrine levels, at least in population-based studies, provide a practical guide to the degree of sympathetic nervous activation.

Sympathetic nerve hyperactivity in patients with renal parenchymal disease (renal injury)

Intravascular volume expansion is a major pathogenic factor in renal parenchymal hypertension. In these patients, excessive renin secretion relative to volume status and heightened sympathetic nervous activity contributes to hypertension in patients with renal injury. Potential mechanisms include afferent stimuli from the injured kidneys to the brain, reduced baroreceptor sensitivity, abnormal vagal function and endothelial dysfunction in patients with renal dysfunction. ${ }^{49-51}$ Early

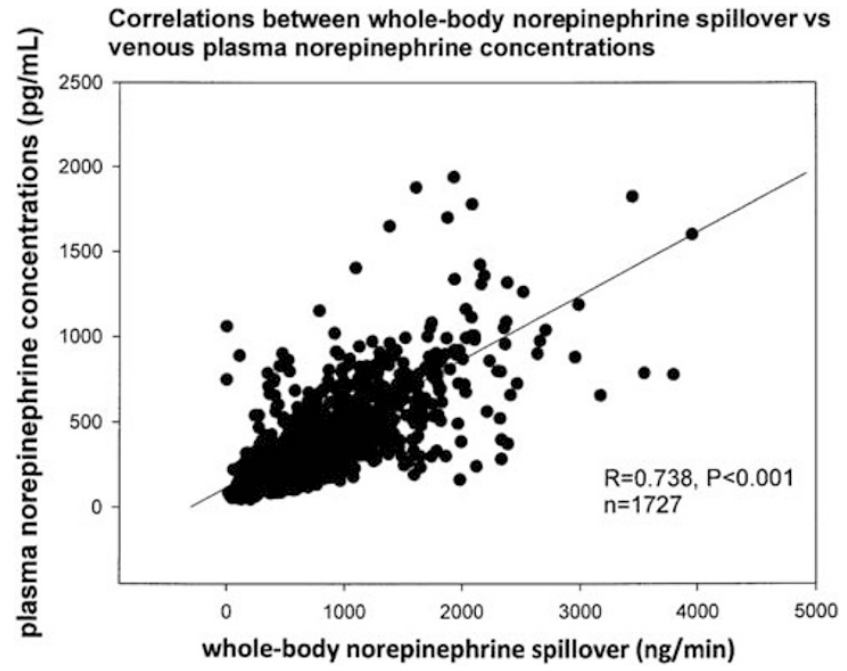

Figure $\mathbf{5}$ Correlation between whole-body norepinephrine spillover and venous plasma norepinephrine concentrations. ${ }^{46}$

glomerular changes in obesity may be the precursors of more severe glomerular injury and progressive impairment of pressure natriuresis. ${ }^{52}$ Klein et al. ${ }^{53}$ reported in hypertensive patients with renal parenchymal disease that sympathetic nervous activity is inappropriately high for the volume status and that reduction of nephron number in itself does not influence sympathetic activity.

Sympathetic nerve hyperactivity in renovascular hypertension Although there is general agreement with regards to the role of the RAS to elevated blood pressure in the early phase of renovascular hypertension, other mechanisms such as sodium retention and the sympathetic nervous activation may contribute to the progression of the disorder. ${ }^{54,55}$ Miyajima et al. ${ }^{56}$ reported increased muscle sympathetic nerve activity in renovascular hypertensive patients. Johansson et al. ${ }^{57}$ found increased muscle sympathetic nerve activity and wholebody norepinephrine spillover in long-term renovascular hypertensive patients compared with normotensive subjects as well as primary hypertensive patients, and they reported sympathetic nerve activity was higher in renovascular hypertensive patients compared with normotensive subjects. Increased muscle sympathetic nerve activity was normalized after successful angioplasty of a renal artery, suggesting that restoration of blood flow to the ischemic kidneys may have eliminated the afferent stimulus that provoked the increased sympathetic nerve drive..$^{58}$

\section{Renal sympathetic nerve hyperactivity may contribute to renal} injury in hypertension and obesity

Elevated renal sympathetic nerve activity is found in animal models of hypertension and in hypertensive humans. ${ }^{59}$ Elevated renal sympathetic nerve activity results in reduced renal excretory function by virtue of its effects on the renal vasculature, the tubules and the juxtaglomerular granular cells, and impaired arterial baroreflex regulation. Intra-renal administration of catecholamines has been shown to elicit an increase in systemic arterial pressure as long as the infusion is continued. The efferent renal sympathetic nerve activity, by exerting a direct influence on renal arteriolar tone, renin release and sodium and water excretion, can interfere with the control of arterial pressure by modifying peripheral resistance, circulating angiotensin II and 
volume balance. The renal sympathetic nerves may contribute to the development of hypertension through the renal excretory defect as well as vascular tone either directly or indirectly through the RAS. Results from renal denervation studies that either attenuated the severity or delayed the development of hypertension in spontaneously hypertensive rats, in DOCA-salt treated rats, in renovascular hypertensive rats, ${ }^{38,40,41,59}$ and in resistant hypertensive patients with normal renal function ${ }^{60}$ support the concept of strong contributions of renal sympathetic nerve activity for hypertension.

Recently, several studies have shown the renal sympathetic denervation was effective in eliciting significant blood pressure reduction in patients with resistant hypertension with suppression of sympathetic nerve remaining evident for at least 12 months. ${ }^{60-62}$ In contrast, Lohmeier et al. ${ }^{63}$ reported that renal denervation affected blood pressure, plasma norepinephrine concentration, plasma renin activity and sodium excretion during the acute phase ( 1 day after renal denervation), but that those were not persist chronically (14 days after renal denervation).

Hall et al. ${ }^{8,39}$ reviewed the importance in the kidneys in the pathogenesis of obesity-related hypertension as obesity raises blood pressure by increasing renal tubular reabsorption, impairing pressure natriuresis, causing volume expansion because of activation of the sympathetic nervous and RASs, and by physical compression of the kidneys, especially when visceral obesity is present. Long-term obesity may cause an increased urinary protein excretion and a gradual loss of nephron function that worsens with time and further exacerbates the hypertension. With prolonged obesity, increased arterial pressure, renal vasodilation and glomerular hyperfiltration, neurohormonal activations including the sympathetic nervous and RASs, and metabolic changes may cause glomerular injury and further impairment of renal-pressure natriuresis, resulting in more severe hypertension and a gradual loss of kidney function. ${ }^{40}$ Relatively small changes in renal artery pressure may lead to large alterations in sodium and water excretions that persisted as long as renal artery pressure is altered.

\section{CLINICAL IMPLICATIONS}

We have discussed the importance of heightened sympathetic nervous activity, especially renal sympathetic hyperactivity, in the pathogenesis of CKD and ESRD in hypertension because the kidneys have a prominent role in fluid and electrolyte regulation and resultant arterial pressure homeostasis through renal sympathetic nerve activity and the RAS. Therefore, one could consider easily that the inhibitors for sympathetic nerve activity or RAS may be the most effective treatments for hypertension in patients with CKD or ESRD.

\section{Renal denervation as a therapy for hypertension}

Sympathetically mediated mechanisms have been implied in the development of hypertension in animal models and in humans. ${ }^{1,20,24}$ Accordingly, in some models of hypertension, complete renal denervation delayed or prevented the development of hypertension. ${ }^{38,59-64}$ Renal denervation attenuates long-term hypertensive effects of angiotensin II. ${ }^{64}$ Renal denervation changes baroreceptor function to attenuate chronic blood pressure elevation. ${ }^{38}$ Further, renal sympathetic nerve activity is modulated by changes in baroreceptor afferent nerve activity under long-term high sodium $\operatorname{diet}^{41}$ and low sodium diet represented by angiotensin II stimulation ${ }^{42}$ in animal models. Disruption of the negative feedback loop between baroreceptor afferents and renal sympathetic nerve activity may lead to impaired regulation of fluid balances, resulting in an elevation in arterial pressure.

Jacob et al. ${ }^{38}$ reported that chronic renal denervation (10 days) lowered arterial pressure regardless of the amount of sodium intakes in Sprague-Dawley rats. Ojeda et al. ${ }^{59}$ suggested that early renal denervation may prevent the development of hypertension in intrauterine growth-restricted offspring who develop hypertension at the pre-pubertal age. They compared blood pressure and renal norepinephrine contents with intrauterine growth restriction in animal models with and without renal denervation. Blood pressure and norepinephrine contents in the kidneys were significantly lower in those with renal denervation compared with sham operated animal after 2 weeks of renal denervation.

A recent multicenter clinical trial showed the effectiveness of catheter-based renal sympathetic nerve denervation in patients with resistant hypertension. ${ }^{60-62}$ After treatment, systolic blood pressure was lowered by $27 \mathrm{~mm} \mathrm{Hg}$ at 12 months with estimated glomerular filtration rate remaining stable (baseline mean office blood pressure was $177 / 101 \mathrm{~mm} \mathrm{Hg}$, patients were initially taking approximately five antihypertensive medications and estimated glomerular filtration rate was $81 \mathrm{ml} \mathrm{min}^{-1}$ per $1.73 \mathrm{~m}^{2}$ ). An attenuation of hypertension of this magnitude by catheter-based renal sympathetic denervation in combination with pharmacologic therapy is likely to be valuable in decreasing the risks of stroke, left ventricular hypertrophy, heart failure and chronic renal failure. ${ }^{63,64}$

\section{Pharmacological treatments for hypertension in patients with ESRD}

Hypertension is common in CKD and is a risk factor for the faster progression of renal damage, and reduction of blood pressure is an efficient way of preventing or slowing the progression of this damage. International guidelines recommend lowering blood pressure to 140/ $90 \mathrm{~mm} \mathrm{Hg}$ or less in patients with uncomplicated hypertension, and to $130 / 80 \mathrm{~mm} \mathrm{Hg}$ or less for patients with diabetic or chronic renal disease. The ESCAPE trial ${ }^{65}$ assessed the long-term renoprotective effect of intensified blood pressure control among 385 children with $\mathrm{CKD}$ treated with a fixed high dose of an angiotensin converting enzyme (ACE) inhibitor, ramipril. This trial showed that intensified blood pressure control, with target 24-h blood pressure levels in the low range of normal, confers a substantial benefit with respect to renal function among children with CKD. Antihypertensive drugs that have direct effects on intra-renal mechanisms may, therefore, have nephron-protective effects additional to those resulting from reductions in arterial blood pressure. ACE inhibitors and angiotensin receptor blockers (ARBs) have beneficial effects on proteinuria and declining renal function that appear to be mediated by factors additional to their effects on blood pressure. These RAS inhibitors are recommended as a first-line antihypertensive approach in patients with CKD. Weir ${ }^{66}$ reviewed the clinical data supporting the use of RAS inhibitions (ACE inhibitors and ARBs) as mono-therapy or combination therapy based on the known role of the RAS in blood pressure regulation and vascular response to injury, and considered the implications of the data for future treatment. Five trials were identified that evaluated the effects of combination therapy with ACE inhibitors and ARBs compared with treatment with either agent alone in different patient populations using different end points. In hypertensive patients with type 2 diabetes and microalbuminuria, combination ACE-inhibitor/ARB therapy resulted in better blood pressure control than either agent alone as well as greater reductions in microalbuminuria. ${ }^{66}$ Compared with monotherapy, dual-RAS inhibitions reduced the occurrence of a doubling of the serum creatinine concentration or ESRD by $60-62 \%$ in patients with non-diabetic renal disease (both $P<0.05$ vs. ACE inhibitor or ARB alone). Combining ACE inhibitors and ARBs to provide more extensive RAS inhibition may provide greater antihypertensive efficacy and end-organ protection than use of 
either class alone. Neumann et al. ${ }^{67}$ reported that RAS inhibitors (ACE inhibitors and ARBs) could reduce blood pressure, but did not normalize sympathetic nervous activity in hypertensive patients with CKD. Klein et al. ${ }^{68}$ compared the effects of enalapril ( $10 \mathrm{mg}$ orally) and losartan ( $100 \mathrm{mg}$ orally) over a 6-week treatment in patients with chronic renal failure. The change in blood pressure and the change in muscle sympathetic nerve activity during the treatments were correlated $(r=0.70$ and $r=0.63$, respectively; both $P<0.05$ ). Baroreceptor sensitivity was not affected by the treatments. These observations support that the RAS inhibitors could suppress the stimulated sympathetic nerve activity associated with reduction on blood pressure.

The addition of diuretics and calcium-channel antagonists to RAS inhibitor therapy is also considered to be a rational strategy to reduce blood pressure and preserve renal function. The ALLHAT study ${ }^{69}$ recommended that thiazide-type diuretics should be the initial therapy for reduction of cardiovascular risk. Either amlodipine or lisinopril was superior to chlorthalidone in preventing ESRD overall, by diabetes status or by renal function level. Thiazides were more effective on preventing heart failure, and new-onset diabetes associated with thiazides did not increase cardiovascular disease outcomes.

Calcium-channel antagonists are a highly heterogeneous class of compounds, and it appears that some agents are more suitable for use in patients with CKD than others. Manidipine is a third-generation dihydropyridine calcium-channel antagonist that blocks both L- and T-type calcium channels. Unlike older-generation dihydropyridines, which preferentially act on L-type channels, manidipine has been shown to have beneficial effects on intrarenal hemodynamics, proteinuria and other measures of renal functional decline in hypertensive patients with chronic renal failure. ${ }^{70}$ Ligtenberg et al. ${ }^{71}$ compared the effects on muscle sympathetic nerve activity between ACE-inhibition using enalapril and calcium-channel antagonist using amlodipine in hypertensive patients with chronic renal failure. Treatment with enalapril normalized blood pressure and muscle sympathetic-nerve activity in the patients and shifted the baroreflex curve to the left, reflecting normal blood pressure levels, without significantly changing sensitivity. In the patients who received amlodipine, treatment also lowered blood pressure but increased muscle sympathetic nerve activity.

In terms of the close contribution of elevated sympathetic nerve activity to renal injury/proteinuria/albuminuria, sympathetic nerve inhibitors may have ameliorative effects on hypertension-related renal injury. Amann et al. ${ }^{72}$ reported that a sub-antihypertensive dose of moxonidine, a centrally acting sympatho-inhibitor, showed ameliorates renal structural and functional damage in sub-totally nephrectomised rats. Renal angiotensin II tissue concentration was not affected by moxonidine.

Bakris et al. ${ }^{73}$ showed that carvedilol was associated with less deterioration on the progress of albuminuria in hypertensive patients with type 2 diabetes compared with metoprolol after 5 months treatment, and that the diminution in deterioration was not explained by blood pressure reduction given the similar blood pressure reduction with each medications. Another study, the Carvedilol-Metoprolol Comparison in Hypertensives (GEMINI) study ${ }^{74}$ involved 1235 hypertensive patients with type 2 diabetes treated with RAS inhibitors. The mean HbAlc increased with metoprolol, but not carvedilol, and insulin sensitivity improved with carvedilol but not metoprolol. Blood pressure was similar between the two groups. Progression to microalbuminuria was less frequent with carvedilol than with metoprolol. These findings indicate that use of carvedilol in the presence of RAS blockade did not affect glycemic control and improved some components of the metabolic syndrome relative to metoprolol in participants with diabetes and hypertension.

\section{CONCLUSIONS}

The role of the sympathetic nervous system in renal injury, ESRD and renovascular hypertension are discussed through a literature review investigating sympathetic nervous mechanisms in hypertension and obesity. Relevant studies of sympathetic nerve activity and $\beta 2$-adrenoceptor polymorphism might contribute to the onset and maintenance of renal injury in healthy subjects and in patients with chronic renal failure and cardiovascular events in ESRD patients. A better understanding of the relationships between sympathetic nerve activity and renal injury will help to develop appropriate treatment strategies targeting renal injury in hypertensive patients with and without CKD. Recently, the possibility of renal sympathetic denervation has been raised with promising results in patients with refractory hypertension and normal renal function with a substantial and sustained reduction in blood pressure persisting up to 12 months without deterioration of renal function. ${ }^{60}$ Clearly, further studies are needed to clarify the mechanisms of the renal injury to prevent the onset or the development of ESRD in hypertensive and obese patients, and to treat renal injury in these patients.

\section{CONFLICT OF INTEREST}

Professor Esler serves on the scientific advisory boards of Servier Australia and Solvay Pharmaceuticals, and Dr Schlaich serves on the advisory board of Servier Australia. Professor Esler and Dr Schlaich and Lambert's laboratories are currently recipients of research funding from Ardian and Allergan. There are no conflicts of interest to disclose between other authors.

1 Mancia G, Grassi G, Giannattasio C, Seravalle G. Sympathetic activation in the pathogenesis of hypertension and progression of organ damage. Hypertension 1999; 34: 724-728.

2 Cohn JN, Levine TB, Olivari MT, Garberg V, Lura D, Francis GS, Simon AB, Rector T. Plasma norepinephrine as a guide to prognosis in patients with chronic congestive heart failure. N Engl J Med 1984; 31: 819-823.

3 Benedict CR, Shelton B, Johnstone DE, Francis G, Greenberg B, Koustam M, Probstfield JL, Yusuf S. For the SOLVD investigators. Prognostic significance of plasma norepinephrine in patients with asymptomatic left ventricular dysfunction. Circulation 1996; 94: 690-697.

4 Ksiazek A, Zatuska W. Sympathetic overactivity in uremia. J Ren Nutr 2008; 18 : 118-121.

5 Petersson MJ, Rundqvist B, Johansson M, Eisenhofer G, Lambert G, Herliz H, Jensen G, Friberg $P$. Increased cardiac sympathetic drive in renovascular hypertension. J Hypertens 2002; 20: 1181-1187.

6 Report of a WHO Expert Committee. Physiological status: the use and interpretation of anthropometry. World Health Organ Tech Rep Ser 1995; 854: 1-452.

7 White SL, Caas A, Atkins RC, Chadban SJ. Chronic kidney disease in the general population. Adv Chronic Dis 2005; 12: 5-13.

8 Hall JE, Jones DW, Kuo JJ, de Silva A, Tallam LS, Liu J. Impact of the obesity epidemic on hypertension and renal disease. Curr Hypertens Rep 2003; 5: 386-392.

9 Zoccali C, Mallamaci F, Parlongo S, Cutrupi S, Benedetto AB, Tripepi G, Bonanno G, Rapisarda F, Fatuzzo P, seminara G, Cateliotti A, Stancanelli B, Malatino S. Plasma norepinephrine predicts survival and incident cardiovascular events in patients with end-stage renal disease. Circulation 2002; 105: 1354-1359.

10 Iseki K, Ikemiya Y, Kinjo K, Inoue T, Iseki C, Takishita S. Body mass index and the risk of development of end-stage renal disease in a screened cohort. Kidney Int 2004; 65: 1870-1876

11 Colditz GA, Willett WC, Rotnizky A, Manson JE. Weight gain as a risk for clinical diabetes mellitus in women. Ann Intern Med 1995; 122: 481-486.

12 Chen J, Muntner P, Hamm LL, Jones DW, Batuman V, Fonseca V, Whelton PK, He J. The metabolic syndrome and chronic kidney disease in US adults. Ann Intern Med 2004; 140: 167-174.

13 Garrison RJ, Kannel WB, Stokes III J, Castelli WP. Incidence and precursors of hypertension in young adults: the Framingham offspring study. Prev Med 1987; 16: 235-251. 
14 Tsukamoto Y. End-stage renal disease (ESRD) and its treatment in Japan. Nephron Dial Transplant 2008; 23: 2447-2450.

15 Masuo K, Mikami H, Ogihara T, Tuck ML. Weight gain-induced blood pressure elevation. Hypertension 2000; 35: 1135-1140.

16 Masuo K, Kawaguchi H, Mikami H, Ogihara T, Tuck ML. Serum uric acid and plasma norepinephrine concentrations predict subsequent weight gain and blood pressure elevation. Hypertension 2003; 42: 474-480.

17 Masuo K, Mikami H, Ogihara T, Tuck ML. Sympathetic nerve hyperactivity precedes hyperinsulinemia and blood pressure elevation in young, nonobese Japanese population. Am J Hypertens 1997; 10: 77-83.

18 Masuo K, Mikaki H, Ogihara T, Tuck ML. Familial hypertension, insulin, sympathetic activity and blood pressure elevation. Hypertension 1998; 32: 96-100.

19 Masuo K, Mikami H, Ogihara T, Tuck ML. Familial obesity, sympathetic activation and blood pressure level. Blood Press 2001; 10: 199-204.

20 Masuo K. Obesity-related hypertension: role of the sympathetic nervous system, insulin, asnd leptin. Curr Hypertens Rep 2002; 4: 112-118.

21 Masuo K, Katsuya T, Sugimoto K, Kawaguchi H, Rakugi H, Ogihara T, Tuck ML. High plasma norepinephrine levels associated with $\beta 2$-adrenoceptor polymorphisms predict future renal damage in nonobese normotensive individuals. Hypertens Res 2007; 30 503-511.

22 Zoccali C, Mallamaci F, Tripepi G, Parlongo S, Cutrupi S, Benedetto FA, Cataliotti A, Malatino $S$. Norepinephrine and concentric hypertrophy in patients with end-stage renal disease. Hypertension 2002; 40: 41-46.

23 Masuo K, Mikami H, Ogihara T, Tuck M. Hormonal mechanisms in blood pressure reduction during hemodialysis in patients with chronic renal failure. Hypertens Res 1995; 18 (Suppl 1): S201-S-203.

24 Masuo K, Lambert GW, Rakugi H, Ogihara T, Esler MD. Neurovascular role of sympathetic nervous system and beta-adrenoceptor polymorphisms in obesity and hypertension. Curr Hypertens Reviews 2008; 4: 121-130.

25 Masuo K, Katsuya T, Fu Y, Rakugi H, Ogihara T, Tuck ML. Beta2- and beta3-adrenergic receptor polymorphisms are related to the onset of weight gain and blood pressure elevation over 5 years. Circulation 2005; 111: 3429-3434.

26 Masuo K, Katsuya T, Fu Y, Rakugi H, Ogihara T, Tuck ML. Beta2-adrenoceptor polymorphisms relate to insulin resistance and sympathetic overactivity as early markers of metabolic disease in nonobese, normotensive individuals. Am J Hypertens 2005; 8: 1009-1014.

27 Masuo K, Katsuya T, Kawaguchi H, Fu Y, Rakugi H, Ogihara T, Tuck ML. Beta2 adrenoceptor polymorphisms relate to obesity through blunted leptin-mediated sympathetic activation. Am J Hypertens 2006; 19: 1084-1091.

28 Masuo K, Katsuya T, Kawaguchi H, Sugimoto K, Rakugi H, Ogihara T, Tuck ML. Beta2-and beta3-adrenoceptor polymorphisms relate to subsequent weight gain and blood pressure elevation in obese normotensive individuals. Hypertens Res 2006; 29: 951-959.

29 Bigazzi R, Bianchi S, Baldari D, Campese VM. Microalbuminuria predicts cardiovascular events and renal insufficiency in patients with essential hypertension. $J$ Hypertens 1998; 16: 1325-1333.

30 Schrader J, Luders S, kulschewski A, Hammersen F, Zuchner C, Venneklass U, Schrandt G, Schneider M, Rangoonwala B, Berger J, Dominiak P, Zidek W. Microalbuminuria and tubular proteinuria as risk predictors of cardiovascular morbidity and mortality in essential hypertension: final results of a prospective long-term study (MARPLE Study). J Hypertens 2006; 24: 541-548.

31 Yudkin JS, Forrest RD, Jackson CA. Microalbuminuria as predictor of vascular disease in non-diabetic subjects. Islington Diabetes Survey Lancet 1988; 2: 530-533.

32 Farbom P, Wahlstrand B, Almgren P, Skrtic S, Lanke J, Weiss L, Kjeldsen S, Hender T, Melander 0 . Interaction between renal function and microalbuminuria for cardiovascular risk in hypertension: the Nordic Diltiazen Study. Hypertension 2008; 52: $115-122$.

33 Hillege HL, Girbes ARJ, de Kam PJ, Boomsma F, de Zeeuw D, Charlesworth A, Hampton $J R$, van Veldhuisen DJ. Renal function, neurohormonal activation, and survival in patients with chronic heart failure. Circulation 2000; 102: 203-210.

34 Mena-Martin FJ, Martin-Escudero JC, Simal-Blanco F, Carretero-Ares JL, Arzua-Mouronte D, Castrodeza Sanz JJ, Hortega Study Investigators. Influence of asympathetic activity on blood pressure and vascular damage evaluated by means of urinary albumin excretion. J Clin Hypertens (Greenwich) 2006; 8: 619-624.

35 Rao F, Wessel J, Wen G, Zhang L, Rana BK, Kennedy BP, Greenwood TA, Salem RM, Chen Y, Chen Y, Khandrika S, Hamilton BA, Smith DW, Holstein-Rathlou NH, Ziegler MG, Schork NJ, O'Connor DT. Renal albumin excretion. Twin studies identify influences of heredity, environment, and adrenergic pathway polymorphism. Hypertension 2007; 49: 1015-1031

36 Schlaich MP, Socratous F, Hennebry S, Eikelis N, Lambert EA, Straznicky N, Esler MD, Lambert GW. Sympathetic activation in chronic renal failure. J Am Soc Nephrol 2009; 20: 933-939.

37 Hausberg M, kosch M, Hamelink P, Barenbrock M, Hohage H, Kisters K, Dietl KH, Dahn KH. Sympathetic nerve activity in end-stage renal disease. Circulation 2002; 106: 1974-1979.

38 Jacob P, Ariza P, Osborn JW. Renal denervation chronically lower arterial pressure independent of dietary sodium intake in normal rats. Am J Physiol Heart Circ Physiol 2003; 284: H2302-H2310.

39 Hall JE. The kidney, hypertension, and obesity. Hypertension 2003; 41 (Part 2): 625-633.

$40 \mathrm{Hall}$ JE. Mechanisms of abnormal renal sodium handling in obesity hypertension. Am J Hypertens 1997; 10: S49-S55.

41 Lohmeier TE, Lohmeier JR, Reckelhoff JF, Hildebrandt DA. Sustained influence of the renal nerves to attenuate sodium intake retention in angiotensin hypertension. $A m ~ J$ Physiol Regul Interg Comp Physiol 2001; 281: R434-R443.
42 Burke SL, Evans RG, Moretti JL, Head GA. Levels of renal and extrarenal sympathetic drive in angiotensin II-induced hypertension. Hypertension 2008; 51: 878-883.

43 Philips JK. Pathogenesis of hypertension in renal failure: role of the sympathetic nervous system and renal afferents. Clin Exp Pharmacol Physiol 2005; 32: 415-418.

44 Grassi G, Seravalle G, Arenare F, Buccianti G, Furiani S, Ilardo V, Bolla G, Mancia G. Behaviour of regional adrenergic outflow in mild-to-moderate renal failure. J Hypertens 2009; 27: 562-566.

45 Erami C, Zhang H, Ho JG, French DM, Faber JE. 1-adrenoceptor stimulation directly induces growth of vascular wall in vivo. Am J Physiol Heart Circ Physiol 2002; 283: H1577-H1587.

46 Masuo K, Straznicky NE, Lambert GW, Esler MD. Obesity and obesity-related hypertension: Role of the sympathetic nervous system and $\beta$-adrenoceptor polymorphisms. In: Kaneko M (ed). Sympathetic Neorvous System Research Developments. Nova Science Publishers: New York, 2007, pp 67-92.

47 Straznicky NE, Lambert EA, Lambert GW, Masuo K, Esler MD, Nestle PJ. Effects of dietary weight loss on sympathetic activity and cardiac risk factors associated with the metabolic syndrome. J Clin Endocrinol Metab 2005; 90: 5998-6005.

48 Esler M, Straznicky N, Eikelis N, Masuo K, Lambert G, Lambert E. Mechanisms of sympathetic activation in obesity-related hypertension. Hypertension 2006; 48: 787-796.

49 Vecchione C, Maffei A, Colella S, Aretini A, Poulet R, Frati G, Gentile MT, Fratta L, Trimarco V, Trimarco B, Lembo G. Leptin effects on endothelial nitric oxide is mediated through Akt-endothelial nitric oxide synthase phosphorylation pathway. Diabetes 2002; 51: 168-173.

50 Lembo G, Vecchione C, Fratta L, Marino G, Trimarco V, D’Amati G, Trimarco B. Leptin induces direct vasodilation through distinct endothelial mechanisms. Diabetes 2000; 49: 293-297.

51 Beltowski J, Wojcicka G, Borkowska E. Human leptin stimulates systemic nitric oxide production in the rat. Obes Res 2002; 10: 939-946.

52 Wesson DE, Kurtzman NA, Prommer JP. Massive obesity and nephrotic proteinuria with a normal renal biopsy. Nephron 1985; 40: 235-237.

53 Klein IH, Ligtenberg G, Neumann J, Oey PL, Koomans HA, Blankestijn PJ. Sympathetic nerve activity is inappropriately increased in chronic renal disease. J Am Soc Nephrol 2003; 14: 3239-3244.

54 Brown JJ, Davies DL, Morton JJ, Robertson JI, Cuesta V, Lever AF, Padfield PL, Trust P. Mechanism of renal hypertension. Lancet 1976; 1: 1219-1221.

55 Suzuki H, Ferrario CM, Speth RC, Brosnihan KB, Smeby RR, de Silva P. Alterations in plasma and cerebrospinal fluid norepinephrine and angiotensin II during the development of renal hypertension in conscious dogs. Hypertension 1983; 5: I-139-I-148.

56 Miyajima E, Yamada Y, Toshida Y, Matsuoka T, Shionoiri H, Tochikubo O, Ishi M. Muscle sympathetic nerve activity in renovascular hypertension and primary aldosteronism. Hypertension 1997; 17: 1057-1062.

57 Johansson M, Elam M, Rundqvist B, Eisenhofer G, Herlitz H, Lambert G, Friberg P. Increased sympathetic nerve activity in renovascular hypertension. Circulation 1999; 99: 2357-2542.

58 Esler M, Jennings G, Biviano B, Lambert G, Haking G. Mechanism of elevated plasma noradrenaline in the course of essential hypertension. J Cardiovasc Pharmacol 1986; 8: 539-544.

59 Ojeda NB, Johnson WR, Dwyer TM, Alexander BT. Early renal denervation prevents development of hypertension in growth-restricted offspring. Clin Exp Pharmacol Physiol 2007; 34: 1212-1216.

60 Krum H, Schlaich M, Whitbourn R, Sobotka DA, Sadowski J, Bertus K, Kapelak B, Walton A, Sievert H, Thambar S, Abraham WT, Esler M. Catheter-based renal sympathetic denervation for resistant hypertension: a multicentre safety and proof-ofprinciple cohort study. Lancet 2009; 373: 1275-1281.

61 Schlaich MP, Sobotka PA, Krum H, Whitbourn R, Walton A, Esler MD. Renal denervation as a therapeutic approach for hypertension. Novel implications for an old concept. Hypertension 2009; 54: 1195-1201.

62 Hendel MD, Collister JP. Renal denervation attenuates long-term hypertensive effects of angiotensin II in the rat. Clin Exp Pharmacol Physiol 2006; 33: 1225-1230.

63 Katholi RE, Rocha-Singh KJ. The role of renal sympathetic nerves in hypertension: has percutaneus renal denervation refocused attention on their clinical significance? Prog Cardiovasc Dis 2009; 52: 243-248.

64 Lohmeier TE, Hildebrandt DA, Dwyer TM, Barrett AM, Irwin ED, Rossing MA, Kieval RS. Renal denervation does not abolish sustained baroreflex-mediated reductions in arterial pressure. Hypertension 2007; 49: 373-379.

65 Wuhi E, Trivelli A, Picca S, litwin M, Peco-Antic A, Zurowska A, Testa S, Jankauskiene A, Emre S, Caldas-Afonso A, Anarat A, Niaudet P, Mir S, Bakkaloglu A, Enke B, Montini G, Wingen AM, Sallay P, Jeck N, Berg U, Caliskan S, Wygoda S, HohbachHohenfellner K, Dusek J, Urasinski T, Arbeiter K, Neuhaus T, Gellermann J, Drozdz D, Fischbach M, Moller K, Wigger M, Peruzzi L, Mehis O, Schaefer F. Strict blood-pressure control and progression of renal failure in children. N Engl J Med 2009; 361: 1639-1650.

66 Weir MR. Effects of renin-angiotensin system inhibition on end-organ protection: can we do better? Clin Ther 2007; 29: 1803-1824

67 Neumann J, Ligtenberg G, Klein IH, Boer P, Oey PL, Koomans HA, Blankestijn PJ. Sympathetic hyperactivity in hypertensive chronic kidney disease patients is reduced during standard treatment. Hypertension 2007; 49: 506-510.

68 Klein IH, Ligtenberg G, Oey PL, Koomans HA, Blankestijn PJ. Enalapril and losartan reduce sympathetic hyperactivity in patients with chronic renal failure. J Am Soc Nephrol 2003; 14: 425-430.

69 Wright JT Jr, Probstfield JL, Cushman WC, Pressel SL, Cutler JA, Davis BR, Einhorn PT, Rahman M, Whelton PK, Ford CE, Haywood LJ, Margolis KL, Oparil S, Black HR, 
Alderman MH, ALLHAT Collaborative Research Group. ALLHAT findings revised in the context of subsequent analyses, other trials, and meta-analyses. Arch Intern Med 2009; 169: 832-842.

70 Wenzel RR. Renal protection in hypertensive patients: selection of antihypertensive therapy. Drug 2005; 65(Suppl 2): 29-39.

71 Ligtenberg G, Blankestijn PJ, Oey PL, Klein IH, Dijkhorst-Oei LT, Boomsma F, Wieneke GH, van Huffelen AC, Koomans HA. Reduction of sympathetic hyperactivity by enalapril in patients with chronic renal failure. $N$ Eng/ J Med 1999; 340: 1321-1328.

72 Amann K, Rump LC, Simonaviciene A, Oberhauser V, Wessels S, Orth SR, Gross ML, Koch A, Bielenberg GW, Van Kats JP, Ehmke H, Mall G, Ritz E. Effects of low dose sympathetic inhibition on glomerulosclerosis and albuminuria in subtotally nephrectomised rats. J Am Soc Nephrol 2000; 11: 1469-1478.

73 Bakris GL, Fonseca V, Katholi RE, McGill JB, Messerli F, Phillips RA, Raskin P, Wright Jr JT, Waterhouse B, Lukas MA, Anderson KM, Bell DS, GEMINI Investigators. Different effects of beta-blockers on albuminuria in patients with type 2 diabetes. Hypertension 2005; 46: 1309-1315.

74 Bakris GL, Fonseca V, Katholl RE, McGill JB, Messerli FH, Phillips RA, Raskin P, Wright Jr JT, Oakes R, Lukas MA, Anderson KM, Bell DS, GEMINI Investigators. Metabolic effects of carvedilol vs metoprolol in patients with type 2 diabetes mellitus and hypertension: a randomized controlled trial. JAMA 2004; 292: 2227-2236 